\title{
PRODUÇÃO AGROECONÔMICA DA RÚCULA FERTILIZADA COM DIFERENTES QUANTIDADES DE Calotropis Procera
}

\author{
AGROECONÓMIC RENDIMIENTO DE RÚCULA FERTILIZADO CON \\ DIFERENTES CANTIDADES DE Calotropis Procera
}

\section{AGROECONOMIC PRODUCTION OF THE ROCKET FERTILIZED WITH DIFFERENT AMOUNTS OF Calotropis Procera}

\author{
Kássya Jemima Borges de OLIVEIRA ${ }^{1}$ \\ Jailma Suerda Silva de LIMA ${ }^{2}$ \\ Ana Paula da Silva SOARES ${ }^{3}$ \\ Francisco BEZERRA NETO ${ }^{4}$ \\ Paulo Cássio Alves LINHARES ${ }^{5}$
}

RESUMO: O uso de adubos orgânicos originados de espécies espontâneas da Caatinga é uma alternativa que pode proporcionar uma boa eficiência agrícola e econômica na produção de hortaliças. Assim, objetivou-se com este trabalho avaliar o desempenho agroeconômico da rúcula em função de diferentes quantidades de Calotropis procera incorporadas ao solo. A pesquisa foi conduzida no período de janeiro a fevereiro de 2014 na Fazenda Experimental Rafael Fernandes, Mossoró-RN. O delineamento experimental utilizado foi em blocos completos casualizados, com cinco tratamentos e cinco repetições. Os tratamentos consistiram de cinco quantidades de $C$. procera incorporadas ao solo (30, 40, 50, 60 e $70 \mathrm{t} \mathrm{ha}^{-1}$ em base seca). As características avaliadas foram: altura de plantas, números de folhas por planta, rendimento de massa verde e massa seca da parte aérea. Além disso, os indicadores econômicos de renda bruta; renda líquida; taxa de retorno e índice de lucratividade foram determinados. A incorporação ao solo de C. procera influenciou positivamente o desempenho produtivo da rúcula, onde a quantidade de $70 \mathrm{t} \mathrm{ha}^{-1}$ produziu maior rendimento $\left(18,86 \mathrm{tha}^{-1}\right)$, demonstrando a facilidade dessa planta como adubo orgânico para a produção sustentável desse cultivo.

Palavras-chave: Eruca sativa L.; adubos orgânicos; indicadores econômicos.

\footnotetext{
${ }^{1}$ Universidade Federal Rural do Semi-Árido. Programa de Pós-graduação em Fitotecnia. Mestre em Fitotecnia. Departamento de Ciências Vegetais. kassyajemima@gmail.com

${ }^{2}$ Universidade Federal Rural do Semi-Árido. Programa de Pós-graduação em Fitotecnia. Professora Adjunto III da Universidade Federal Rural do Semi-Árido (UFERSA). Departamento de Ciências Vegetais. jailmaagro@gmail.com

${ }^{3}$ Universidade Federal Rural do Semi-Árido. Graduanda em Agronomia. Departamento de Ciências Vegetais. cantoraanapaulasoares@ hotmail.com

${ }^{4}$ Programa de Pós-graduação em Fitotecnia. Professor Titular da Universidade Federal Rural do Semi-Árido (UFERSA). Departamento de Ciências Vegetais. bezerra@ufersa.edu.br

${ }^{5}$ Universidade Federal Rural do Semi-Árido. Programa de Pós-graduação em Fitotecnia. Mestrando em Fitotecnia. Departamento de Ciências Vegetais. paulo_linhares2011@ @otmail.com
} 
RESUMEN: El uso de abonos orgánicos, oriundos de especies de plantas silvestres, es una alternativa que puede proporcionar una buena eficiencia agrícola y económica en la producción de hortalizas. Así, el objetivo de este estudio fue evaluar el desempeño agroeconómico del cultivo de rúcula sometidas a diferentes cantidades de Calotropis procera incorporadas al suelo. La investigación se realizó en el periodo de enero a febrero de 2014 en la Finca Experimental Rafael Fernandes, en Mossoró-RN. El diseño experimental fue el de bloque completamente al azar con cinco tratamientos y cinco repeticiones. Los tratamientos consistieron en la incorporación al suelo de cinco dosis de sustrato seco de $C$. procera, equivalentes a 30, 40, 50, 60 y $70 \mathrm{t} \mathrm{ha}^{-1}$. Las características evaluadas fueron: altura de planta, número de hojas, rendimiento de masa verde y materia seca de la parte aérea de la planta de rúcula. También fueron determinados los indicadores económicos ingreso bruto y neto, tasa de retorno e índice de rentabilidad. La incorporación al suelo de C. procera influyó positivamente en el desempeño productivo de la rúcula, donde la dosis de $70 \mathrm{t} \mathrm{ha}^{-1}$ produjo el mayor rendimiento $\left(18,86 \mathrm{t} \mathrm{ha}^{-1}\right)$, demostrando la factibilidad de esa planta como abono orgánico para la producción sostenible de ese cultivo.

Palabras clave: Eruca sativa L.; abonos orgánicos; indicadores económicos.

\begin{abstract}
The use of organic fertilizers derived from spontaneous species of the Caatinga, is an alternative that can provide good agricultural and economic efficiency in the production of vegetables. Thus, the aim of this study was to evaluate the agroeconomic performance of the rocket in function of different amounts of Calotropis procera incorporated into the soil. The research was of conducted in the period January-February 2014, in the Experimental Farm Rafael Fernandes, Mossoró-RN. The experimental design was a randomized complete block with five treatments and five repetitions. The treatments consisted of five amounts of $C$. procera incorporated into the soil $\left(30,40,50,60\right.$ and $70 \mathrm{t} \mathrm{ha}^{-1}$ on a dry basis). The characteristics evaluated were: plant height, number of leaves per plant, green mass yield and dry mass of shoots. In addition, the economic indicators of gross income; net income; rate of return and profit margin were determined. The incorporating into the soil with C. procera positively influenced the productive performance of the rocket, where the amount of $70 \mathrm{t} \mathrm{ha}^{-1}$ produced higher yield $\left(18,86 \mathrm{t} \mathrm{ha}^{-1}\right)$, demonstrating the ease of this plant as organic fertilizer for sustainable production of this crop.
\end{abstract}

Keywords: Eruca sativa L.; organic fertilizers; economic indicators.

\title{
Introdução
}

A produção de hortaliças na agricultura familiar tem sua produção voltada ao consumo da família, e a venda do seu excedente, sendo característico o seu cultivo intensivo, exigindo cada vez mais o aprimoramento de técnicas para obtenção de produtos de melhor qualidade e com quantidade (ALVES et al., 2012). 
Esse tipo de produção, principalmente as folhosas, que são consumidas em maior quantidade, é característico dos pequenos produtores, por não terem recursos hídricos suficientes para o cultivo de culturas de ciclo longo, com isso, as plantas de ciclo curto é uma alternativa para geração de renda na propriedade.

A alface e o coentro são as principais folhosas plantadas e consumidas na região, sendo que, a demanda por outras hortaliças, como a rúcula, tende a crescer, pois a população tem diversificado o consumo devido à busca por uma alimentação mais equilibrada, além da chegada de pessoas provenientes de outras regiões que, geralmente, apresentam hábito alimentar diferenciado (SOUZA et al., 2015).

A rúcula é uma hortaliça folhosa que apresenta características de cultivo semelhantes às do coentro, em que facilita sua produção pelos pequenos. Para a produção das hortaliças, os olericultores têm utilizado o esterco bovino como fonte de adubação, que muitas vezes não se torna viável, pois muitos não têm este adubo em sua propriedade, necessitando de insumos externos, aumentando os custos de produção (ALMEIDA, et al., 2015a).

No entanto, entre os adubos orgânicos, o de origem vegetal tem se destacado, tornandose uma técnica utilizada na produção de hortaliças folhosas e tuberosas no Nordeste brasileiro (SILVA et al., 2013). Esta prática caracteriza-se por adubação verde, que tem como estratégia aumentar a quantidade de nutrientes no solo, (principalmente nitrogênio), aumentar a porcentagem de matéria orgânica do solo e diminuir a acidez do solo e o alumínio tóxico, benefícios esses, muito importantes para a sustentabilidade dos sistemas de produção agrícola (BEZERRA NETO et al., 2014; SARTORI et al., 2011), melhora a estrutura e o arejamento do solo e sua capacidade de armazenar umidade, além de ter efeito regulador na temperatura do solo (SILVA et al., 2013). Retarda a fixação do fósforo, aumentando a capacidade de troca catiônica (CTC), ajudando a segurar o potássio, cálcio, magnésio e outros nutrientes em formas disponíveis para as raízes, protegendo-as de lavagem ou lixiviação pela água das chuvas ou de irrigação (BATISTA et al., 2012).

Espécies do bioma Caatinga têm surgido como alternativa à prática de adubação verde. Entre essas espécies espontâneas encontram-se a jitirana (Merremia aegyptia L.), a flor-deseda (Calotropis procera (Ait.) R.Br.) e o mata-pasto (Senna uniflora L.).

Alguns trabalhos comprovam a eficiência agronômica da adubação verde com espécies espontâneas da Caatinga no cultivo de hortaliças, entre eles, Souza et al., (2015) registraram uma produtividade de 46,91 $\mathrm{t} \mathrm{ha}^{-1}$ de rúcula, quando adubada com $14 \mathrm{t} \mathrm{ha}^{-1}$ de flor-de-seda aos 30 dias antes da semeadura da cultura. Almeida et al., (2015b) obtiveram maior 
produtividade de alface $\left(15,78 \mathrm{t} \mathrm{ha}^{-1}\right)$ e maior rendimento de massa verde da rúcula $(4,30 \mathrm{t}$ ha ${ }^{1}$ ), em consorciação, com as quantidades de $36,9 \mathrm{t} \mathrm{ha}^{-1}$ e $37,96 \mathrm{t} \mathrm{ha}^{-1}$ de flor-de-seda incorporadas ao solo, respectivamente.

Diante disso, este trabalho teve como objetivo avaliar o desempenho agroeconômico da rúcula em função de diferentes quantidades de Calotropis procera incorporadas ao solo.

\section{Material e Métodos}

A pesquisa foi conduzida na Fazenda Experimental Rafael Fernandes, localizada no distrito de Alagoinha, distante $20 \mathrm{~km}$ da sede do município de Mossoró (5'11' S e $37^{\circ} 20^{\prime} \mathrm{W}$, 18 m de altitude), em solo classificado como Latossolo Vermelho Amarelo Argissólico franco arenoso (EMBRAPA, 2006), no período de janeiro a fevereiro de 2014. O clima na região, pela classificação de Köppen, é BsWh, ou seja, seco, muito quente e com estação chuvosa no verão (CARMO FILHO; ESPÍNOLA SOBRINHO; MAIA NETO, 1991).

O delineamento experimental utilizado foi em blocos casualizados completos, com cinco tratamentos e cinco repetições. Os tratamentos consistiram de cinco quantidades de florde-seda (Calotropis procera), (30; 40; 50; 60 e $70 \mathrm{t} \mathrm{ha}^{-1}$ em base seca) incorporadas ao solo. Cada parcela experimental apresentou uma área total de $1,44 \mathrm{~m}^{2}(1,20 \mathrm{~m}$ x 1,20 m) contendo 80 plantas no espaçamento de $0,20 \mathrm{~m}$ x $0,05 \mathrm{~m}$. A área útil de plantas foi de $0,80 \mathrm{~m}^{2}(1,0 \mathrm{~m} \times$ 0,80m) contendo 80 plantas. A cultivar de rúcula utilizada foi a "Cultivada", indicada para cultivo na região nordeste.

Antes da instalação do experimento em campo, foram coletadas amostras de solo, a uma camada de $0-20 \mathrm{~cm}$. Estas foram processadas e analisadas no Laboratório de Química e Fertilidade de Solos da Universidade Federal Rural do Semi-Árido (UFERSA), fornecendo os seguintes resultados: $\mathrm{pH}=7,06 ; \mathrm{P}=9,4 \mathrm{mg} \mathrm{dm}^{-3} ; \mathrm{K}=64,2 \mathrm{mg} \mathrm{dm}^{-3} ; \mathrm{Ca}=1,57 \mathrm{cmol}_{\mathrm{c}} \mathrm{dm}^{-3}$; $\mathrm{Mg}=0,5 \mathrm{cmol}_{\mathrm{c}} \mathrm{dm}^{-3} ; \mathrm{Na}=20,0 \mathrm{mg} \mathrm{dm}^{-3} ; \mathrm{CE}=0,08 \mathrm{dS} \mathrm{m}^{-1} ; \mathrm{M} . \mathrm{O}=7,06 \mathrm{~g} \mathrm{~kg}^{-1} ; \mathrm{SB}=2,32$ $\mathrm{cmol}_{\mathrm{c}} \mathrm{dm}^{-3} ; \mathrm{CTC}=2,73 \mathrm{cmol}_{\mathrm{c}} \mathrm{dm}^{-3} ; \mathrm{PST}=3 \% ; \mathrm{t}=2,3 \mathrm{cmol}_{\mathrm{c}} \mathrm{dm}^{-3} \mathrm{e} \mathrm{V}=85 \%$.

O preparo do solo constituiu-se de limpeza manual da área, com o auxílio de uma enxada, seguida de uma gradagem e levantamento dos canteiros, realizado por trator. Após a confecção dos canteiros, uma solarização foi realizada com plástico transparente 'Vulcabrilho Bril Fles' de 30 micras durante 45 dias com o intuito de reduzir a população de fitopatógenos do solo que por ventura viessem a prejudicar o desenvolvimento e a produtividade da cultura da rúcula. 
Foram realizadas coletas de flor-de-seda no município de Quixeré-CE, na propriedade da empresa Cimento Apodi, no início do período de floração, quando a planta apresentava a maior concentração de nutrientes. As plantas foram trituradas em máquina forrageira convencional, obtendo-se fragmentos entre 2,0 e 3,0 cm. Foram secas ao sol e acondicionadas em sacos de ráfia permanecendo com umidade média de $10 \%$, conforme metodologia de Batista et al., (2013), e armazenadas para serem posteriormente incorporadas ao solo. Amostras de flor-de-seda foram encaminhadas ao Laboratório do Departamento de Solos da UFERSA, onde se realizaram as análises químicas das mesmas, fornecendo os seguintes resultados: $\mathrm{N}=20,3 \mathrm{~g} \mathrm{~kg}^{-1} ; \mathrm{P}=2,7 \mathrm{~g} \mathrm{~kg}^{-1} ; \mathrm{K}=36,63 \mathrm{~g} \mathrm{~kg}^{-1} ; \mathrm{Ca}=7,05 \mathrm{~g} \mathrm{~kg}^{-1} ; \mathrm{Mg}=12,38 \mathrm{~g}$ $\mathrm{kg}^{-1} ; \mathrm{Fe}=601,67 \mathrm{mg} \mathrm{kg}^{-1} ; \mathrm{Mn}=194 \mathrm{mg} \mathrm{kg}^{-1} ; \mathrm{Zn}=31,23 \mathrm{mg} \mathrm{kg}^{-1} ; \mathrm{Cu}=7,8 \mathrm{mg} \mathrm{kg}^{-1}$ e $\mathrm{Na}=$ $4519 \mathrm{mg} \mathrm{kg}^{-1}$.

A incorporação do material vegetal foi realizada 20 dias antes do plantio, incorporandose $100 \%$ das quantidades estudadas. Após a incorporação da flor-de-seda ao solo, realizou-se irrigações diárias, por micro aspersão, com turno de rega parcelado em duas aplicações

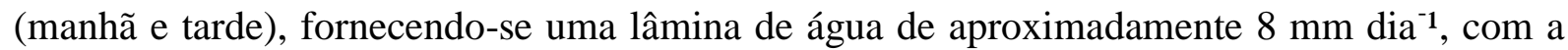
finalidade de favorecer atividade microbiota do solo no processo de decomposição do material vegetal.

O plantio da rúcula foi realizado em semeadura direta com covas de aproximadamente $2,0 \mathrm{~cm}$ de profundidade. O desbaste da rúcula foi realizado onze dias após o plantio, deixando-se apenas uma planta por cova. Capinas manuais foram realizadas sempre que necessário, para manter as plantas no limpo. A colheita foi realizada aos 29 dias após a semeadura.

As características avaliadas foram: altura de plantas (mensurada numa amostra de vinte plantas, retiradas aleatoriamente da área útil, obtida com auxílio de uma régua graduada em centímetros, a partir do nível do solo até a extremidade das folhas mais altas, e que foi expressa em centímetros); número de folhas por planta (também foi contabilizado na mesma amostra de vinte plantas, através da contagem do número de folhas maiores que $3 \mathrm{~cm}$ de comprimento, partindo-se das folhas basais até a última folha aberta); rendimento de massa verde (foi avaliado através da massa fresca da parte aérea de todas as plantas da área útil, e expressa em $\mathrm{t} \mathrm{ha}^{-1}$ ) e massa seca da parte aérea (foi extraída da mesma amostra de vinte plantas, na qual se determinou a massa seca das plantas em estufa com circulação de ar forçada a $65^{\circ} \mathrm{C}$ até atingir massa constante, e expressa em $\mathrm{t} \mathrm{ha}{ }^{-1}$.

A renda bruta de cada parcela foi obtida multiplicando-se a produtividade comercial da 
cultura em cada tratamento pelo valor do produto, que foi $\left(\mathrm{R} \$ 2,00 \mathrm{~kg}^{-1}\right)$ de rúcula pago ao produtor no mês de janeiro de 2014. A renda líquida foi obtida subtraindo-se da renda bruta os custos de produção. Foram considerados, custos de produção da rúcula, os preços de insumos e serviços vigentes no mês de janeiro de 2014 na cidade de Mossoró-RN. Obteve-se a taxa de retorno por real investido através da relação entre a renda bruta e o custo de produção de cada tratamento. O índice de lucratividade foi obtido da relação entre a renda líquida e a renda bruta, expressa em porcentagem (OLIVEIRA et al., 2004).

Análises de variância nas características avaliadas foram realizadas através do aplicativo software SISVAR (FERREIRA, 2011). O procedimento de ajustamento de curvas de resposta foi realizado através do software Table curve (JANDEL SCIENTIFIC, 1991) para avaliar cada característica em função das doses de flor-seda incorporadas.

\section{Resultados e Discussão}

Observou-se aumento na altura de plantas, número de folhas e no rendimento de massa verde de rúcula com o aumento das quantidades de flor-de-seda aplicadas ao solo, obtendo os valores máximos de $22,75 \mathrm{~cm}, 15$ folhas e $18,86 \mathrm{t} \mathrm{ha}^{-1}$, respectivamente, na quantidade de $70 \mathrm{t}$ $\mathrm{ha}^{-1}$ de flor-de-seda (Figuras 1A a 1C). Este aumento dessas características com as quantidades crescentes de flor-de-seda se deve, em parte, à maior disponibilidade de nutrientes, principalmente N, P e K liberados pela flor-de-seda.

Batista et al., (2013), afirmam que sendo a rúcula bastante exigente em nitrogênio e potássio, e esses elementos foram os mais disponibilizados, principalmente nas maiores quantidades incorporadas, resultando assim, em maior desenvolvimento vegetativo. Conforme Filgueira, (2008) o fornecimento de quantidades adequadas de nitrogênio favorece o desenvolvimento vegetativo, expande a área fotossintética, ativa e eleva o potencial produtivo da cultura. Esse comportamento evidencia que as plantas são responsivas quanto ao fornecimento de matéria orgânica ao solo.

Oliveira et al., (2010), encontraram resultados semelhantes para a altura de plantas, sendo no primeiro cultivo uma altura de $(23,9 \mathrm{~cm})$ e na rebrota de $(22,1 \mathrm{~cm})$, em experimento avaliando adubação orgânica. Andrade Filho (2012), verificou valores inferiores aos obtidos nesse trabalho, com as quantidades crescentes de flor-de-seda, obtendo-se o valor de 14,09 cm na altura de plantas de rúcula na quantidade $13,09 \mathrm{t} \mathrm{ha}^{-1}$. 

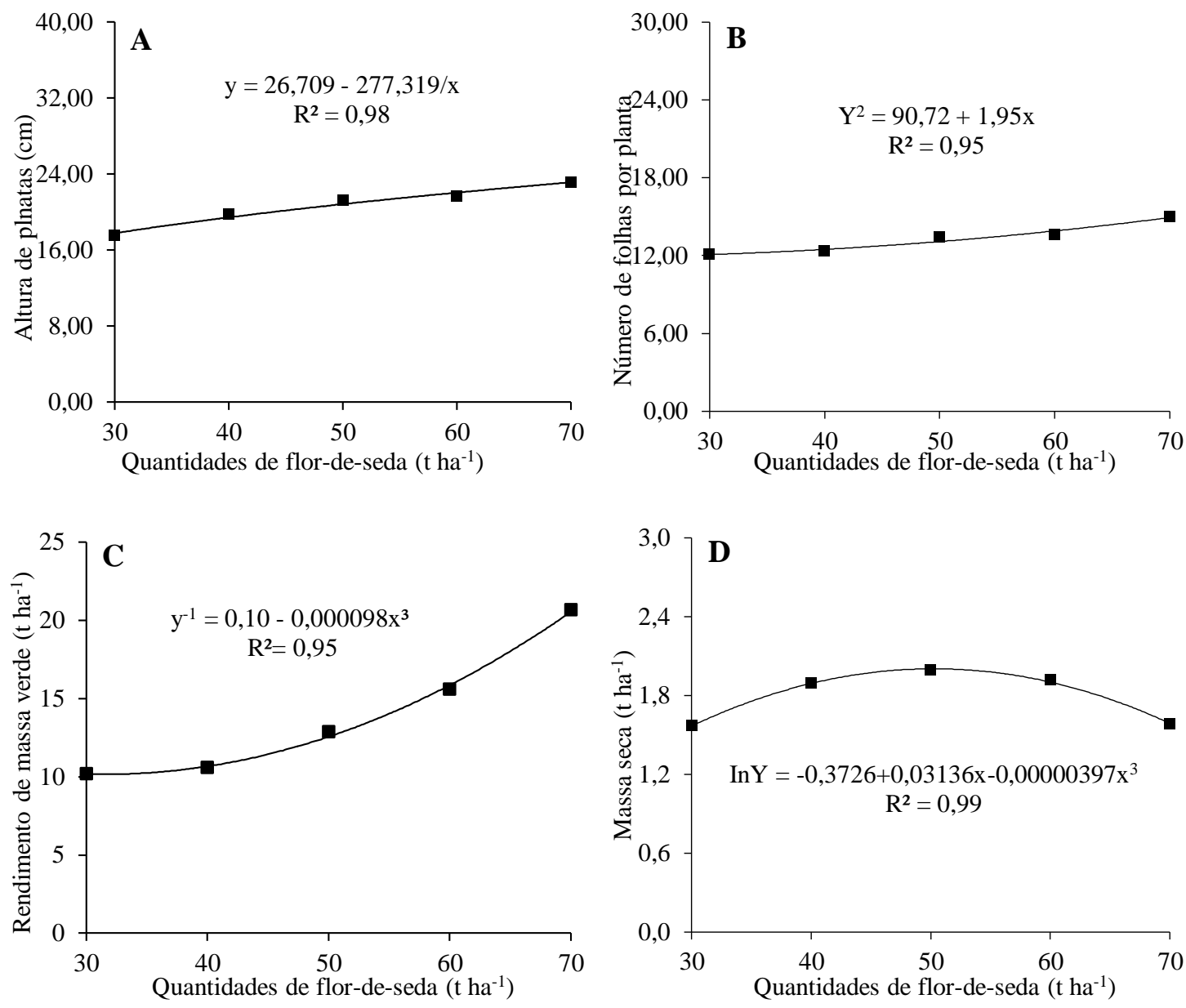

Figura 1. Altura de plantas (A), número de folhas por planta (B), rendimento de massa verde (C) e massa seca (D) de rúcula, em função de diferentes quantidades de flor-de-seda incorporadas ao solo.

Resultados inferiores para o número de folhas por planta foram encontrados por Oliveira et al., (2010), tanto no primeiro cultivo como na rebrota da rúcula, onde verificaram 10,6 e 11 folhas por planta, respectivamente, em experimento avaliando adubação orgânica. Almeida et al., (2015a) registraram uma resposta linear na produção de folhas, o qual apresentou um número médio de 10,0 folhas planta ${ }^{-1}$, com a quantidade de $3,0 \mathrm{~kg} \mathrm{~m}^{-2}$ de florde-seda, em experimento avaliando o efeito residual da jitirana, flor-de-seda e mata-pasto no cultivo da rúcula em sucessão a beterraba. Souza (2014), obteve resultados semelhantes, apresentando uma média de 16,90 folhas por planta de rúcula, com 15,6 t ha ${ }^{-1}$ de flor-de-seda incorporadas ao solo. 
Os resultados apresentados no rendimento de massa verde (Figura 1C), se devem, supostamente, a maior disponibilidade de macro e micronutrientes, liberados pelo adubo, objetivando a melhoria na fertilidade do solo. De acordo com Batista et al., (2013), a adubação com espécies vegetais que ocorrem de forma espontânea na região, também favorece os aspectos microbiológicos do solo, com aumento na quantidade de actinomicetos, fungos e bactérias, benéficos ao crescimento das plantas, uma vez que atuam na solubilização de nutrientes do adubo verde.

Souza et al., (2015) obtiveram no rendimento de massa verde de rúcula, que a medida em que se aumentou a quantidade de flor-de-seda houve um incremento na produtividade da cultura, resultados que corroboram com os da presente pesquisa. Resultados superiores foram obtidos por Barros Junior et al., (2012), onde verificaram que a medida que se aumentou a quantidade de adubo verde, ocorreu um crescimento no rendimento de massa verde, alcançando um valor máximo de $36,79 \mathrm{t} \mathrm{ha}^{-1}$ na massa verde de rúcula na quantidade de 15,6 $\mathrm{t} \mathrm{ha}^{-1}$ do adubo verde flor-de-seda. Silva (2012) observou valor máximo de rendimento de massa verde $\left(7,9 \mathrm{t} \mathrm{ha}^{-1}\right)$, na combinação de $45 \mathrm{t} \mathrm{ha}^{-1}$ de flor-de-seda com o tempo de 20 dias antes da semeadura da rúcula, divergindo dos resultados apresentados na presente pesquisa.

Para a massa seca da parte aérea, observou-se um aumento desta característica em função das quantidades crescentes de flor-de-seda incorporadas ao solo, alcançando o valor máximo de 2,01 t ha-1, na quantidade de 51,28 $\mathrm{t} \mathrm{ha}^{-1}$ de flor-de-seda adicionadas ao solo, decrescendo em seguida até a última quantidade incorporada ao solo (Figura 1D). Resultados inferiores foram apresentados por Silva (2012), que encontrou valor máximo de massa seca da parte aérea $\left(1,4 \mathrm{t} \mathrm{ha}^{-1}\right)$, na combinação de $45 \mathrm{t} \mathrm{ha}^{-1}$ de flor-de-seda com o tempo de 20 dias antes da semeadura da rúcula. Já Souza (2014), obteve resultados semelhantes, com um aumento no rendimento de massa seca de rúcula $\left(2,37 \mathrm{t} \mathrm{ha}^{-1}\right.$, na primavera-verão, e 2,44 $\mathrm{tha}^{-1}$, no outono), entre a menor $\left(5,4 \mathrm{t} \mathrm{ha}^{-1}\right)$ e a maior $\left(15,6 \mathrm{t} \mathrm{ha}^{-1}\right)$ quantidade de flor-de-seda incorporada ao solo.

Com relação aos indicadores econômicos, renda bruta, renda líquida, taxa de retorno e índice de lucratividade, observou-se aumento nos valores com as doses crescentes de flor-deseda incorporadas ao solo, alcançando os valores máximos de $\mathrm{R} \$ 40.622,48 ; \mathrm{R} \$ 30.091,04$; 3,60 por real investido e $72,26 \%$, respetivamente, na quantidade de $70 \mathrm{t} \mathrm{ha}^{-1}$ de flor-de-seda adicionada ao solo (Figuras 2A a 2D). 

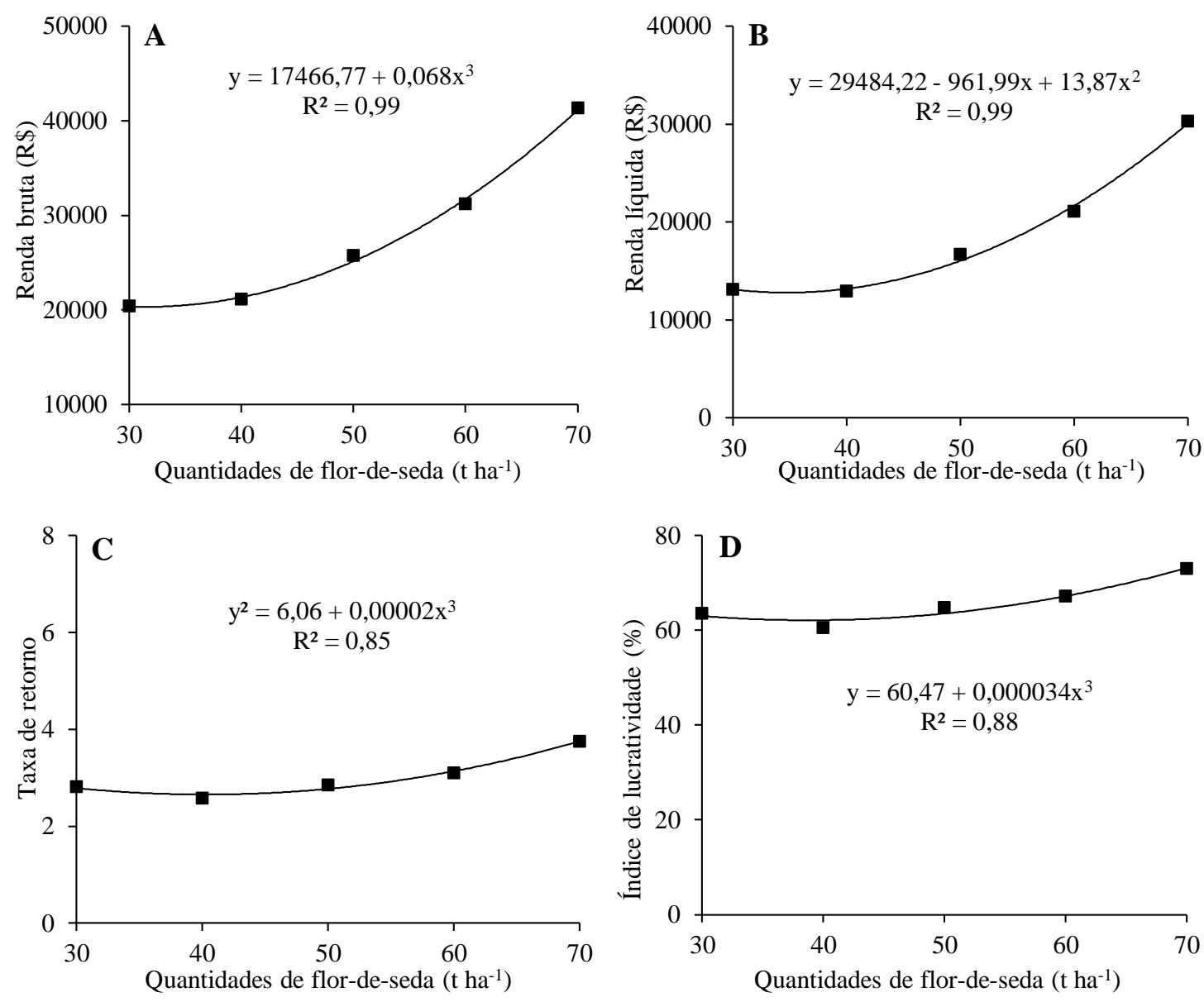

Figura 2. Renda bruta (A), renda líquida (B), taxa de retorno (C) e índice de lucratividade (D) na produção de um hectare de rúcula, em função de diferentes quantidades de flor-de-seda incorporadas ao solo.

No entanto, o melhor desempenho da rúcula foi obtido pela quantidade de flor-de-seda incorporada ao solo de $70 \mathrm{t} \mathrm{ha}^{-1}$, ditada pela renda líquida, considerada um dos indicadores que expressa melhor o valor econômico dos sistemas de cultivos, do que a renda bruta, já que naquela se encontram deduzidos os custos de produção (BEZERRA NETO et al., 2012). Estes resultados se devem ao fato de que a rúcula respondeu bem à adubação verde, e que esses indicadores econômicos promissores advieram do melhor aproveitamento dos recursos ambientais pelas plantas de rúcula proporcionadas pelas quantidades de flor-de-seda testadas. Assim, a eficiência agronômica do desempenho produtivo da rúcula foi traduzida em eficiência econômica.

Com isto, o agricultor mesmo com poucos recursos para investimento na atividade, pode ter a flor-de-seda como uma alternativa de produção e lucratividade, pois, a mesma apresenta alto potencial de rebrota (ANDRADE et al., 2008). A flor-de-seda é uma alternativa 
de adubo para a agricultura orgânica, porém com menos restrições em relação ao uso de estercos de currais e seus derivados (SILVA et al., 2011). Vale lembrar que este adubo verde é conservado na forma de feno (teor de umidade de 10\%), favorecendo seu armazenamento por vários anos, sem prejuízo às suas qualidades nutricionais (SOUZA et al., 2015). Este feno também apresenta perspectivas promissoras de uso na produção de caprinos e ovinos (PEREIRA et al., 2010; SILVA et al., 2010), tornando-se de dupla finalidade de uso no Semiárido.

\section{Conclusões}

A incorporação ao solo de Calotropis procera influenciou positivamente o desempenho produtivo da rúcula.

O melhor desempenho agroeconômico da rúcula foi obtido na quantidade de $70 \mathrm{t} \mathrm{ha}^{-1} \mathrm{de}$ flor-de-seda incorporada ao solo.

\section{Referências}

ALMEIDA, A. E. S.; BEZERRA NETO, F.; COSTA, L. R.; SILVA, M. L.; LIMA, J. S. S.; BARROS JÚNIOR, A. P. Eficiência agronômica do consórcio alface-rúcula fertilizado com flor-de-seda. Revista Caatinga, Mossoró, v. 28, n. 3, p. 79-85, 2015 b.

ALMEIDA, A. M. B.; LINHARES, P. C. F.; FILHO, J. L.; NEVES, A. P. M.; MORAIS, S. L. S. Efeito residual da jitirana, flor-de-seda e mata-pasto no cultivo da rúcula em sucessão a beterraba. Revista Verde de Agroecologia e Desenvolvimento Sustentável, Pombal, v. 10, n. 2, p. 42-48, 2015a.

ALVES, R. F.; LINHARES, P. C. F.; PEREIRA, M. F. S.; FILHO, J. L.; SOUSA, A. J. P.; PAIVA, A. C. C. Desempenho agronômico da Rúcula sob diferentes proporções de jitirana e Flor-de-seda em sistema orgânico. Agropecuária Científica no Semiárido, Patos, v. 8, n. 4, p. 107-112, 2012.

ANDRADE FILHO, F. C. Bicultivo de folhosas consorciadas com beterraba em função de adubação com flor-de-seda e densidades populacionais. 2012. $94 \mathrm{f}$. Tese (Doutorado em Fitotecnia) - Universidade Federal Rural do Semi-árido, Mossoró, 2012.

ANDRADE, M. V. M.; SILVA, D. S.; ANDRADE, A. P.; MEDEIROS, A. N.; PIMENTA FILHO, E. C.; CÂNDIDO, M. J. D.; CALDAS PINTO, M. S. Produtividade e qualidade da Flor-de-seda em diferentes densidades e sistemas de plantio. Revista Brasileira de Zootecnia, Viçosa, v. 37, n. 1, p. 1-8, 2008. 
BARROS JUNIOR, A. P.; SILVA, E. F.; SILVEIRA, L. M.; BEZERRA NETO, F.; SANTANA, M. S.; SANTOS, M. G.; MARTINS, B. N. M. Cultivo da rúcula utilizando diferentes quantidades e tempos de incorporação no solo do adubo verde Flor-de-seda. Horticultura Brasileira, Brasília, v. 30, n. 2, (Suplemento - CD Rom), julho 2012.

BATISTA, M. A. V.; BEZERRA NETO, F.; AMBROSIO, M. M. Q.; GUIMARÃES, L. M. S.; SARAIVA, J. P. B.; SILVA, M. L. Atributos microbiológicos do solo e produtividade de rabanete influenciados pelo uso de espécies espontâneas. Horticultura Brasileira, Brasília, v.31, n.4, p.587-594, 2013.

BATISTA, M. A.V.; VIERIA, L. A.; SOUSA, J. P.; FREITAS, J. D. B.; BEZERRA NETO, F. Efeito de diferentes fontes de adubação sobre a produção de alface no município de IguatuCE. Revista Caatinga, Mossoró, v. 25, n. 3, p. 8-11, 2012.

BEZERRA NETO, F.; OLIVEIRA, L. J.; SANTOS, A. P.; LIMA, J. S. S.; SILVA, Í. N. Otimização agroeconômica da cenoura fertilizada com diferentes doses de jitirana. Revista Ciência Agronômica, Fortaleza, v. 45, n. 2, p. 305-311, 2014.

BEZERRA NETO, F.; PORTO, V. C. N.; GOMES, E. G.; CECÍllo FILHO, A. B.; MOREIRA, J. N. Assessment of agroeconomic indices in polycultures of lettuce, rocket and carrot through uni- and multivariate approaches in semi-arid Brazil. Ecological Indicators, Kidlington, v. 14, p. 11-17, 2012.

CARMO FILHO, F.; ESPÍNOLA SOBRINHO, J.; MAIA NETO, J. M. Dados climatológicos de Mossoró: Um município semi-árido nordestino. Mossoró: ESAM, 1991. 121p. (Coleção Mossoroense, série C, 30).

EMBRAPA - EMPRESA BRASILEIRA DE PESQUISA AGROPECUÁRIA. Centro Nacional de Pesquisa de solos. Sistema brasileiro de classificação de solos. 2 a ed. Rio de Janeiro: Embrapa, 2006. 306p.

FERREIRA, D. F. Sisvar: a computer statistical analysis system. Ciência e agrotecnologia, Lavras, v. 35, n. 6, p. 1039-1042, 2011.

FILGUEIRA, F. A. R. Novo manual de olericultura: Agrotecnologia moderna na produção e comercialização de hortaliças. Viçosa: UFV, 2008. 421p.

JANDEL SCIENTIFIC. Table curve: curve fitting software. Corte Madera, CA: Jandel Scientific, 1991. 280p.

OLIVEIRA, E. Q.; BEZERRA NETO, F.; NEGREIROS, M. Z.; BARROS JÚNIOR, A. P. Desempenho agroeconômico do bicultivo de alface em sistema solteiro e consorciado com cenoura. Horticultura Brasileira, Brasília, v. 22, n. 4, p. 712-717, 2004.

OLIVEIRA, E. Q.; SOUZA R. J.; CRUZ, M. C. M.; MARQUES, V. B.; FRANÇA, A. C. Produtividade de alface e rúcula, em sistema consorciado, sob adubação orgânica e mineral. Horticultura Brasileira, Brasília, v.28, n.1, p. 36-40, 2010.

PEREIRA, G. F.; ARAÚJO, G. G. L.; MEDEIROS, A. N.; COSTA LIMA, G. F.; COELHO GRACINDO, Â. P. A.; JÚNIOR, V. L.; FERNANDES JÚNIOR, F. C.; CÂNDIDO, E. P. Consumo e disgestibilidade do feno de flor-de-seda em dietas para cabras leiteiras. Revista 
Brasileira de Saúde e Produção Animal, Salvador, v. 11, n. 1, p. 79-90, 2010.

SARTORI, V. C.; SILVA-RIBEIRO, R. T.; SCUR, L.; PANSERA, M. R.; DIEL RUPP, L. C.; VENTURIN, L. Adubação verde e compostagem: estratégias de manejo do solo para conservação das águas. Cartilha para agricultores [recurso eletrônico] - Dados eletrônicos. Caxias do Sul, RS: Educs, 2011.

SILVA, M. L.; BEZERRA NETO, F.; LINHARES, P. C. F.; BEZERRA, A. K. H. Produção de cenoura fertilizada com flor-de-seda (Calotropis procera (Ait.) R.Br.). Revista Ciência Agronômica, Fortaleza, v. 44, n. 4, p. 732-740, 2013.

SILVA, M. L.; BEZERRA NETO, F.; LINHARES, P. C. F.; SÁ, J. R.; LIMA, J. S. S.; BARROS JÚNIOR, A. P. Produção de beterraba fertilizada com jitirana em diferentes doses e tempos de incorporação ao solo. Revista Brasileira de Engenharia Agrícola e Ambiental, Campina Grande, v. 15, n. 8, p. 801-809, 2011.

SILVA, J. G. M.; COSTA LIMA, G. F.; AGUIAR, E. M.; MElO, A. A. S.; TELES RÊGO, M. M. Cactáceas nativas associadas a fenos de flor de seda e sabiá na alimentação de borregos. Revista Caatinga, Mossoró, v. 23, n. 3, p. 123-129, 2010.

SILVA, M. L. Viabilidade agronômica de hortaliças fertilizadas com flor-de-seda (Calotropis procera (Ait.) R.Br.). 2012. 83f. Tese (Doutorado em Agronomia: Fitotecnia) Universidade Federal Rural do Semi-Árido (UFERSA), Mossoró-RN.

SOUZA, E. G. F. BARROS JÚNIOR, A. P.; BEZERRA NETO, F.; SILVEIRA, L. M.; LEAL, Y. H.; ALVES, M. J. G. Rentabilidade da rúcula fertilizada com biomassa de flor-deseda em função da época de cultivo. Revista Caatinga, Mossoró, v. 28, n. 1, p. 65-77, 2015.

SOUZA, E. G. F. Produtividade e rentabilidade de rúcula adubada com espécie espontânea, em duas épocas de cultivo. 2014. 61f. Dissertação (Mestrado em Produção Vegetal) - Universidade Federal Rural de Pernambuco, Serra Talhada-PE. 